\title{
First mutation in the FSHR cytoplasmic tail identified in a non-pregnant woman with spontaneous ovarian hyperstimulation syndrome
}

Justine Hugon-Rodin ${ }^{1 \dagger}$, Charlotte Sonigo ${ }^{2,3 \dagger}$, Anne Gompel ${ }^{1}$, Catherine Dodé ${ }^{4}$, Michael Grynberg², Nadine Binart ${ }^{3}$ and Isabelle Beau ${ }^{3^{*}}$

\begin{abstract}
Background: Spontaneous ovarian hyperstimulation syndrome (sOHSS) is a rare event occurring mostly during natural pregnancy. Among described etiologies, some activating mutations of FSH receptor (FSHR) have been identified.

Case presentation: We report hereby the case of a non-pregnant women with three episodes of sOHSS. Hormonal evaluation was normal and no pituitary adenoma was detected. However, genetic analysis identified a novel heterozygous FSHR mutation (c.1901 G>A). This R634H mutation is the first described in the cytoplasmic tail of the receptor. Functional analysis failed to reveal constitutive activity of the mutant but a decreased cAMP production in response to FSH. The weak activity of this mutant is correlated with a markedly reduced cell surface expression.

Conclusion: Pathophysiology of non gestationnal sOHSS is still ill established. The molecular characterization of this new mutant indicates that it might not be at play. Therefore, further investigations are needed to improve knowledge of the molecular mechanism of this syndrome.
\end{abstract}

Keywords: FSHR, Spontaneous ovarian hyperstimulation syndrome, Mutation, CAMP

\section{Background}

Ovarian hyperstimulation syndrome (OHSS) is an iatrogenic complication of supraphysiological ovulation induction in infertile patients. Evidence indicates that human chorionic gonadotrophin (hCG) plays a crucial role in the pathophysiology of this condition [1]. OHSS is characterized by ovarian enlargement due to multiple cysts together with abdominal distension. The pathogenesis of OHSS results in part from the production of several cytokines, probably enhanced by hCG, administered for final follicular maturation and further produced in case of pregnancy [2]. Clinical presentation is similar in spontaneous OHSS (sOHSS), a rare event mostly reported after natural pregnancy. sOHSS may result

* Correspondence: isabelle.beau@u-psud.fr

${ }^{\dagger}$ Equal contributors

${ }^{3}$ Inserm U1185, Univ Paris-Sud, University Paris Saclay, Le Kremlin Bicêtre

94276, France

Full list of author information is available at the end of the article from high serum hCG levels encountered in multiple or molar pregnancies. However, Follicular Stimulating Hormone (FSH)-producing pituitary adenomas (FSHoma) or neuroendocrine tumors, activating mutations of the FSH receptor (FSHR), and hypothyroidism may also constitute risky situations $[3,4]$. Five activating FSHR mutants have already been described in pregnant patients with sOHSS [5-9]. These gain-of-function mutations increase the sensitivity to hCG and/or to thyroid-stimulating hormone (TSH). By contrast, an impairment of FSHR function may cause severe folliculogenesis disorders such as ovarian failure $[10,11]$. In the present paper, we report a case of non-gestational sOHSS associated with a novel FSHR mutation.

\section{Case presentation}

A 26-year-old woman was referred for a medical treatment after 3 ovarian torsions. After spontaneous 
puberty, she had been naturally pregnant one time and after normal evolution, in particular without sOHSS, delivered one healthy baby. She used combined hormonal contraception $(\mathrm{CHC})$ before and after pregnancy. Two years after the delivery, she was hospitalized 3 times in one year for pelvic pain. Laparoscopy was performed each time and showed torsions of adnexa with multicystic ovaries, while she used CHC. Finally, a right salpingo-oophorectomy revealed hemorrhagic infarction. One month later, pelvic ultrasonography revealed an enlarged $7 \times 5 \mathrm{~cm}$ left ovary containing multiple cysts in the pelvis (Fig. 1a) confirmed by pelvic Magnetic Resonance Imaging (MRI) (Fig. 1b). After 6 months of treatment by gonadotropin-releasing hormone agonist, the size of left ovary was restored, without cysts. Etiologic assessment was performed during agonist treatment. Hormonal evaluation showed low serum estradiol $(<43 \mathrm{pmol} / \mathrm{L})$ and anti-Müllerian hormone $(0.8 \mathrm{ng} / \mathrm{mL})$ levels. Gonadotropin values were $<0.5 \mathrm{UI} / \mathrm{L}$ for $\mathrm{LH}$ and $5 \mathrm{UI} / \mathrm{L}$ for FSH. Levels of prolactin, TSH, cortisol and androgens were in the normal range. No adenoma was detected on pituitary MRI. She reported that her mother who had two pregnancies never suffered from OHSS.

\section{Materials and methods DNA sequencing}

Informed consent for DNA sequence analysis was obtained from the patient. DNA was extracted from peripheral blood leukocytes. All exons of the FSHR gene, together with intron-exon boundaries (around $10 \mathrm{pb}$ ) were sequenced using an automated sequencer (PGM life-technologies, AmpliSeq 3.4).

\section{Construction of mutated FSHR}

The mutation was introduced into the pSG5-hFSHR plasmid [12] by oligonucleotide-mediated mutagenesis using QuickChange Site-Directed Mutagenesis Kit (Agilent). The construct was verified by Sanger method sequencing.
Cell culture and transfection

COS-7 cells were grown with $10 \%$ fetal bovine serum in DMEM-F12 medium supplemented with L-glutamine and penicillin-streptomycin at $37{ }^{\circ} \mathrm{C}$ in humidified air containing $5 \% \mathrm{CO}_{2}$. The cells were transfected with plasmids encoding the wild-type (WT) or mutated FSHR using the FuGENE 6 transfection reagent (Promega), according to the manufacturer's protocol.

The efficiency of transfection was assessed by western blot analysis. Cells were lysed and total extracts were loaded onto $7.5 \%$ SDS-polyacrylamide gels. After transferring proteins on nitrocellulose membranes, blots were probed with FSHR323 monoclonal antibody [12] and anti-actin (clone C4, Millipore) antibodies.

\section{cAMP assay}

Forty-eight hours after transfection, the intracellular accumulation of cyclic AMP (cAMP) was measured after incubation for $45 \mathrm{~min}$ with various concentrations of recombinant human FSH (Gonal-Fं, Merck, France) using cAMP complete ELISA kit (Enzo Life Sciences).

\section{Immunofluorescence and confocal microscopy}

FSHR323 was used to study, by indirect immunofluorescence, FSHR expression in transfected COS-7 cells as described previously [13]. For non permeabilized conditions, the antibody was applied on living cells for $1 \mathrm{~h}(\mathrm{~h})$ at $4{ }^{\circ} \mathrm{C}$ in PBS containing $1 \%$ BSA, and the cells were fixed for $15 \mathrm{~min}(\mathrm{~min})$ in $3 \%$ formaldehyde. After saturation with PBS/1\% BSA the cells were incubated for $1 \mathrm{~h}$ with AlexaFluor 555 labeled anti-mouse antibody.

In some experiments, the cells were permeabilized for 4 min with $0.2 \%$ triton in PBS and incubated with FSHR antibody for $2 \mathrm{~h}$ at room temperature and further proceeded as non permeabilized cells. The samples were mounted in DAPI Fluoromont G medium (Southern Biotech). Imaging was carried out on a SP8 Leica confocal microscope.

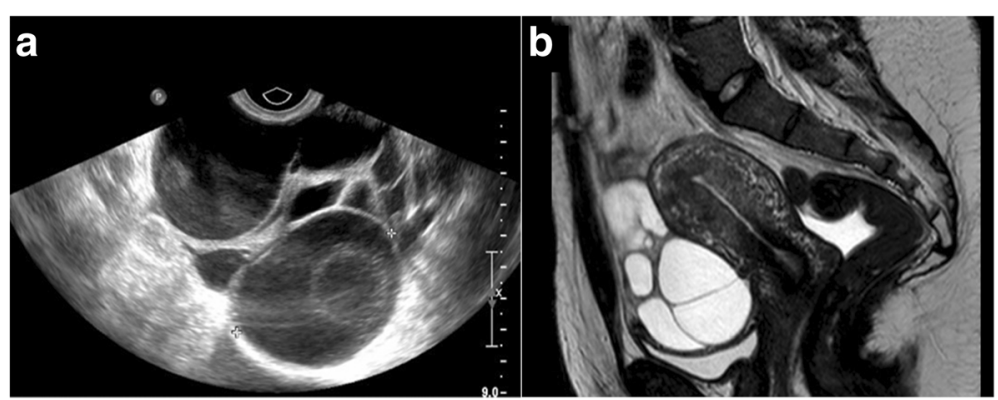

Fig. 1 Multiple ovarian cysts revealed in pelvic ultrasonogaphy and MRI. Pelvic ultrasonography (a) revealed an enlarged 7x5 cm left ovary containing multiple cysts without fluid in the pelvis. This sagittal pelvic Magnetic Resonance Imaging (b) T2 weighted images showed a left multicystic ovary 


\section{Surface immunoprecipitation of wild type and mutated} FSH receptors

Cell surface expression of the wild type and mutated FSHR was analyzed by immunoprecipitation as previously described [14]. Briefly, FSHR antibody was added to the cell surface for one hour at $37{ }^{\circ} \mathrm{C}$. Receptorantibody complexes were extracted, purified and analyzed by western-blot.

\section{Statistical analysis}

Data are expressed as means \pm standard error of the means (SEM) and were analyzed with Prism software (GraphPad version 6.0) by using repeat measures ANOVA (Kruskal-Wallis test) to assess differences between groups followed by appropriated post-hoc comparisons (Dunn's test). The $\mathrm{p}$ values lower than 0.05 were considered statistically significant. Experiments were performed a minimum of three times.

\section{Results}

Sequencing of FSHR gene revealed a heterozygous substitution of a guanine for an adenine in exon 10 (c.1901 G > A), resulting in the substitution of an arginine for histidine at position 634 of the protein (Fig. 2). The p.Arg634His variant (R634H) was referenced with allelic frequency of 0.000041 in the Exome Aggregation Consortium Browser Database. The Arginine 634, located at the beginning of the cytoplasmic tail, is highly conserved among species (Fig. 2a). In silico analysis revealed that p.Arg634His variant was predicted as "possibly damaging" and "deleterious" by Polyphen and SIFT respectively.

This variant was then introduced into an expression vector encoding the FSHR and was transiently transfected into COS-7 cells. The transfection efficiency of the WT and mutated FSHR, assessed by western blot, showed similar level of protein (Fig. 2b).

To evaluate the functional activity of the mutant, we first analyzed the basal production of cAMP by the WT and mutated FSHR. COS-7 cells transfected with expression vector encoding receptor were incubated in DMEM containing $0.5 \mathrm{mM}$ IBMX and the intracellular accumulation of cAMP was quantified. No significant difference in basal cAMP production by cells expressing the wildtype or mutated receptor was observed (Fig. 3a). COS-7 cells expressing either WT or R634H FSHR were then incubated with increasing concentrations of FSH. A cAMP dose-dependent response to FSH was observed in all conditions, but the response of the mutated receptor to high doses of FSH was decreased as compared to the WT. After transfection of COS-7 cells with equal quantities of the WT and mutant FSHR expression vector, mimicking the situation of heterozygous mutation, the response to recombinant FSH was similar to that of the

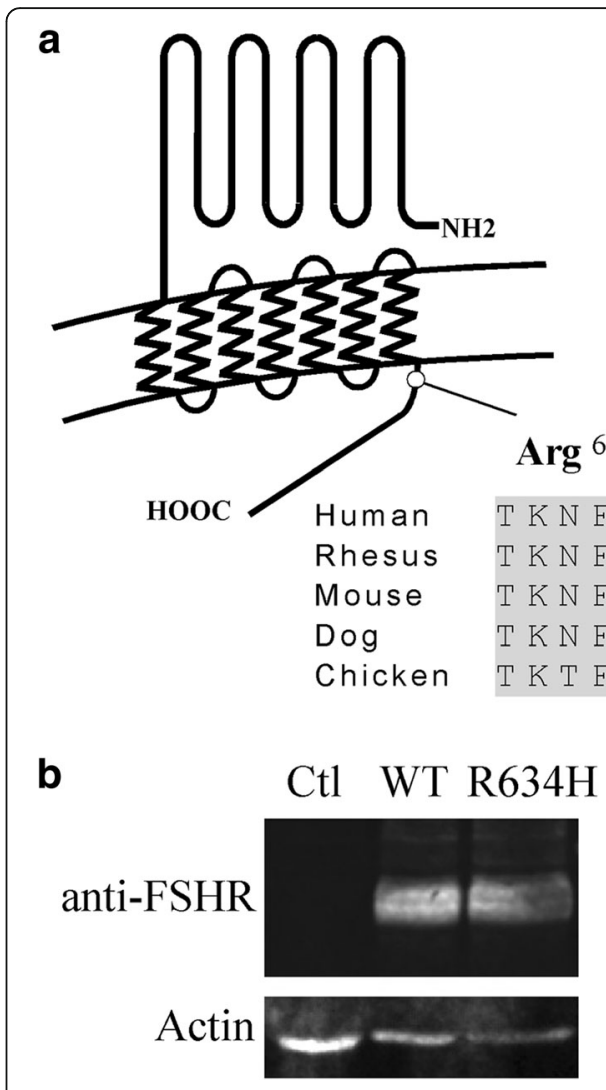

Fig. 2 New FSHR mutation located in the beginning of the cytoplasmic tail and expression level of wild-type and mutated receptor after transfection. a Schematic representation of follicle-stimulating hormone receptor (FSHR) with the location of the $\mathrm{R} 634 \mathrm{H}$ mutation in the beginning of the cytoplasmic tail and sequence alignment of amino-acid from chicken to human. $\mathbf{b}$ The expression level of wild-type (WT) and R634H in transfected COS-7 cells, is shown by western blot using specific antibody

WT receptor alone (Fig. 3b). In the absence of difference of response with high doses of FSH, response to physiological doses (1-5 mUI/mL) was analyzed. No difference between WT and mutated receptors was detected (Fig. 3c). In order to evaluate whether the mutated $\mathrm{R} 634 \mathrm{H}$ mutant became sensitive to other ligands, stimulation with recombinant hCG and TSH were assessed. No accumulation of cAMP was observed in both conditions (data not shown).

To assess the cell surface expression of the mutant, the transfected cells permeabilized or not permeabilized were incubated with FSHR323 antiboby recognizing the ectodomain of FSHR. Confocal microscopy examination of permeabilized cells showed similar expression of WT and mutated receptors (Fig. 3d). Both WT and mutated receptors were observed at the cell surface in nonpermeabilized cells, but the expression of the mutant was markedly reduced compared to the WT receptor (Fig. 3d). In order to quantify the WT and mutated 


\section{a}

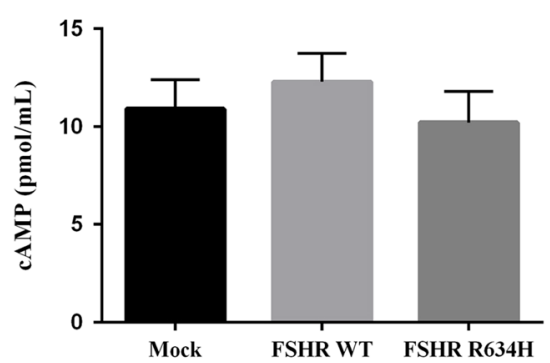

b

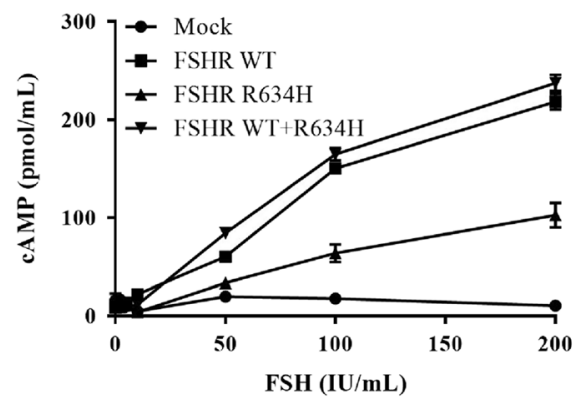

C

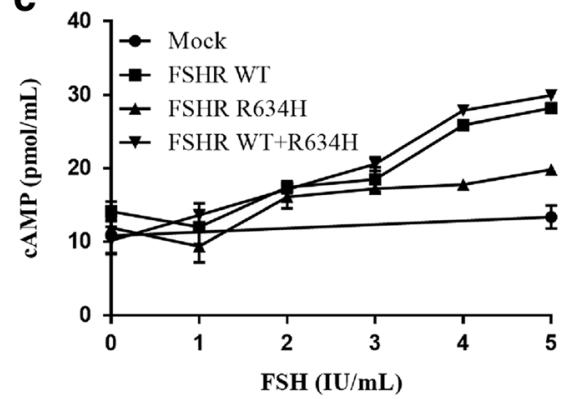

d

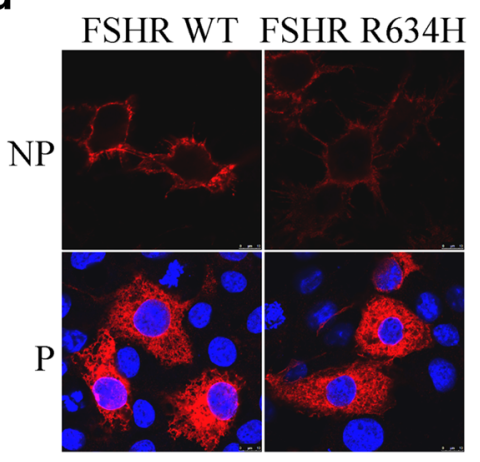

e

Total Surface

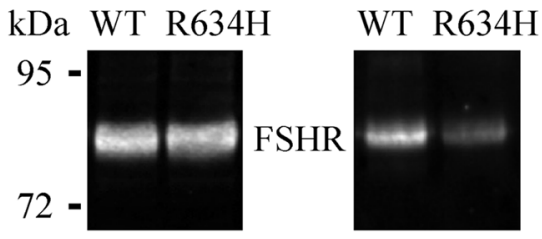

Fig. 3 Functional studies of the wild-type and mutant FSHR. COS-7 cells were transfected with empty (mock) or expression vector encoding WT and/or mutated receptor. COS-7 cells were transfected with empty (mock) or expression vector encoding WT and/or mutated receptor. a Cyclic AMP (CAMP) level observed in transfected cells in the absence of any hormonal stimulation. Graph represents the results of at least three separate experiments performed in duplicate conditions. $\mathbf{b}$ and $\mathbf{c}$ Transfected cells were incubated with increasing concentrations of human follicle-stimulating hormone (FSH) and the accumulation of CAMP was measured. Each graph represents the results (mean \pm SEM) of at least two separate experiments. $\mathbf{d}$ Cell surface expression of WT and mutated FSHRs. Permeabilized (P) or nonpermeabilized (NP) transfected cells were incubated with the FSHR323 antibody. Confocal microscopy was used to study the cellular distribution of receptors. e The membrane expression of the FSHR R634H is decreased. COS-7 cells were transfected with WT or mutated FSHR. Immunoprecipitation of FSHR from total extract (total) or from cell surface (surface) was performed using FSHR323. Immunoprecipitated FSHR was analyzed by western-blotting. Size of the molecular mass is indicated

FSHR at the cell membrane, we performed surface immunoprecipitation experiments. The level of $\mathrm{R} 634 \mathrm{H}$ was decreased by $60 \%$ as compared to the WT FSHR while we detected the same amount of the two receptors in the total extract (Fig. 3e).

\section{Discussion and conclusion}

Even though OHSS is mostly an iatrogenic complication, a consequence of hormonal stimulation in infertile patients [1], some cases may occur spontaneously, in particular during pregnancy [15]. Here, we report a case of sOHSS, resulting in three adnexal torsion, in a nonpregnant woman with normal gonadotropins and thyroid hormones levels and without pituitary adenoma. In our knowledge, just two cases of ovarian torsion had been described. The first one had been described during an episode of thyroiditis, in a patient with an history of two previous episodes of sOHSS during her two pregnancies [16]. The second one occurred in a patient with ectopic hypersecretion of FSH by a pancreatic tumor [4].

Today, only 5 heterozygous activating FSHR mutations have been described [5-9]. The common feature of these 
five mutations is that they have reduced specificity for FSH as they respond to increasing hCG levels that occur during normal pregnancy. Indeed, they become responsive to increasing hCG or TSH concentrations [5-9]. All of them are located either in transmembrane [5, 7-9] or in extracellular FSHR domain [6] and are associated with reduced specificity for FSH.

We described here the first mutation located in the FSHR cytoplasmic tail. The R634H residue belongs to the highly conserved BXXBB motif (where B represents a basic residue and $\mathrm{X}$ a non-basic residue) located in the receptor cytoplasmic tail [17]. When the mutant FSHR was transfected into COS-7 cells in the absence of ligand, no constitutive activation was observed. Moreover, there was a decrease in cAMP production after FSH administration compared to WT and surface cell expression was impaired. These results are in accordance with several studies evaluating the functional role of the cytoplasmic tail of FSHR and particularly the BXXBB motif [17-19]. Indeed, functional analysis revealed that the cytoplasmic-tail of FSHR plays an indispensable role in cell surface receptor trafficking [20] and $\mathrm{BXXBB}$ is particularly important for membrane expression [17, 18]. Moreover, we showed that in heterozygous condition, the response to recombinant FSH was similar to that of the WT receptor alone. In the same way, Zarinán et al. had reported that co-transfection of wild type FSHR with mutant FSHR in the BXXBB of the cytoplasmic tail showed dose-dependent inhibition in cAMP production with increasing amounts of mutant DNA and subsequently rescue of function by co-transfection with wild-type fragments suggesting oligomerization of FSHR [21].

We report, in a young patient suffering from recurrent and unexplained sOHSS, the first FSHR mutation located in the cytoplasmic tail of the receptor. However, contrasting with the phenotype, functional analysis demonstrated that this mutant does not exhibit any constitutive activity. Similarly another reported FSHR variant, M512I, also found in non-pregnant woman with sOHSS, did not demonstrated her involvement in this pathology [22]. Nevertheless, both case reports highlight the importance of performing functional analysis to ensure that new FSHR mutations are actually at play in sOHSS. Further investigations and genetic analysis will be needed to understand the pathophysiology of sOHSS.

\footnotetext{
Abbreviations

CAMP: cyclic Adenosine MonoPhosphate; CHC: Combined hormonal contraception; DNA: Deoxyribo nucleic acid; FSH: Follicular stimulating hormone; FSHoma: FSH-producing pituitary adenomas; FSHR: FSH receptor; hCG: Human chorionic gonadotrophin; LH: Luteinizing hormone; MRI: Magnetic resonance imaging; OHSS: Ovarian hyperstimulation syndrome; SEM: Standard error of the means; sOHSS: Spontaneous OHSS; TSH: Thyroid-Stimulating hormone; WT: Wild-Type
}

\section{Acknowledgements}

We thank V. Nicolas for assistance in confocal microscopy (Plate-forme d'imagerie cellulaire-MIPSIT, University Paris-Sud).

\section{Funding}

Not applicable.

\section{Availability of data and materials}

The datasets used and/or analysed during the current study are available from the corresponding author on reasonable request.

\section{Authors' contributions}

IB, NB and CS designed the study; CD performed the genetic analyses; IB and CS carried out the experiments; $\mathrm{JH}, \mathrm{CS}, \mathrm{NB}$ and IB wrote the manuscript; and $\mathrm{JH}, \mathrm{AG}, \mathrm{CS}$ and $\mathrm{MG}$ managed the patient. All authors read and approved the final manuscript.

\section{Competing interests}

The authors declare that they have no competing interests.

\section{Consent for publication}

Written informed consent for the publication of these details was obtained from the patient.

\section{Ethics approval and consent to participate}

Research procedures were conducted in accordance with institutional guidelines and the Declaration of Helsinki. Informed consent for DNA sequence analysis was obtained from the patient.

\section{Publisher's Note}

Springer Nature remains neutral with regard to jurisdictional claims in published maps and institutional affiliations.

\section{Author details \\ ${ }^{1}$ Gynecology Endocrinology Unit, Port-Royal Cochin Hospital, University Paris Descartes, Paris, France. ${ }^{2}$ Department of Reproductive Medicine and Fertility Preservation, Jean-Verdier Hospital, Bondy, France. IInserm U1185, Univ Paris-Sud, University Paris Saclay, Le Kremlin Bicêtre 94276, France. ${ }^{4}$ Department of Biochemistry and Molecular Genetics, Cochin Hospital, Paris, France.}

Received: 24 October 2016 Accepted: 14 April 2017

Published online: 26 April 2017

\section{References}

1. Fiedler K, Ezcurra D. Predicting and preventing ovarian hyperstimulation syndrome (OHSS): the need for individualized not standardized treatment. Reprod Biol Endocrinol RBE. 2012;10:32.

2. Boothroyd C, Karia S, Andreadis N, Rombauts L, Johnson N, Chapman M, et al. Consensus statement on prevention and detection of ovarian hyperstimulation syndrome. Aust N Z J Obstet Gynaecol. 2015;55:523-34.

3. Panagiotopoulou N, Byers H, Newman WG, Bhatia K. Spontaneous ovarian hyperstimulation syndrome: case report, pathophysiological classification and diagnostic algorithm. Eur J Obstet Gynecol Reprod Biol. 2013;169:143-8.

4. Miras AD, Mogford JT, Wright J, Mendoza NN, Xekouki P, Lakhani A, et al. Ovarian hyperstimulation from ectopic hypersecretion of follicle stimulating hormone. Lancet Lond Engl. 2015;385:392.

5. Smits G, Olatunbosun O, Delbaere A, Pierson R, Vassart G, Costagliola S. Ovarian hyperstimulation syndrome due to a mutation in the follicle-stimulating hormone receptor. N Engl J Med. 2003;349:760-6.

6. De Leener A, Caltabiano G, Erkan S, Idil M, Vassart G, Pardo L, et al. Identification of the first germline mutation in the extracellular domain of the follitropin receptor responsible for spontaneous ovarian hyperstimulation syndrome. Hum Mutat. 2008;29:91-8.

7. De Leener A, Montanelli L, Van Durme J, Chae H, Smits G, Vassart G, et al. Presence and absence of follicle-stimulating hormone receptor mutations provide some insights into spontaneous ovarian hyperstimulation syndrome physiopathology. J Clin Endocrinol Metab. 2006;91:555-62.

8. Vasseur C, Rodien P, Beau I, Desroches A, Gérard C, de Poncheville L, et al. A chorionic gonadotropin-sensitive mutation in the follicle-stimulating hormone 
receptor as a cause of familial gestational spontaneous ovarian hyperstimulation syndrome. N Engl J Med. 2003;349:753-9.

9. Montanelli L, Delbaere A, Di Carlo C, Nappi C, Smits G, Vassart G, et al. A mutation in the follicle-stimulating hormone receptor as a cause of familial spontaneous ovarian hyperstimulation syndrome. J Clin Endocrinol Metab. 2004:89:1255-8.

10. Desai SS, Roy BS, Mahale SD. Mutations and polymorphisms in FSH receptor: functional implications in human reproduction. Reprod Camb Engl. 2013;146: R235-248.

11. Bramble MS, Goldstein EH, Lipson A, Ngun T, Eskin A, Gosschalk JE, et al. A novel follicle-stimulating hormone receptor mutation causing primary ovarian failure: a fertility application of whole exome sequencing. Hum Reprod Oxf Engl. 2016;31:905-14.

12. Vannier B, Loosfelt H, Meduri G, Pichon C, Milgrom E. Anti-human FSH receptor monoclonal antibodies: immunochemical and immunocytochemical characterization of the receptor. Biochemistry (Mosc). 1996;35:1358-66.

13. Beau I, Touraine P, Meduri G, Gougeon A, Desroches A, Matuchansky C, et al. A novel phenotype related to partial loss of function mutations of the follicle stimulating hormone receptor. J Clin Invest. 1998;102:1352-9.

14. Beau I, Groyer-Picard MT, Le Bivic A, Vannier B, Loosfelt H, Milgrom E, et al. The basolateral localization signal of the follicle-stimulating hormone receptor. J Biol Chem. 1998:273:18610-6.

15. Siegel ET, Kim H-G, Nishimoto HK, Layman LC. The molecular basis of impaired follicle-stimulating hormone action: evidence from human mutations and mouse models. Reprod Sci Thousand Oaks Calif. 2013;20:211-33.

16. Di Carlo C, Savoia F, Fabozzi A, Gargano V, Nappi C. A case of ovarian torsion in a patient carrier of a FSH receptor gene mutation previously affected by spontaneous ovarian hyperstimulation syndrome. Gynecol Endocrinol Off J Int Soc Gynecol Endocrinol. 2015;31:105-8.

17. Timossi C, Ortiz-Elizondo C, Pineda DB, Dias JA, Conn PM, Ulloa-Aguirre A. Functional significance of the BBXXB motif reversed present in the cytoplasmic domains of the human follicle-stimulating hormone receptor. Mol Cell Endocrinol. 2004;223:17-26

18. Ulloa-Aguirre A, Uribe A, Zariñán T, Bustos-Jaimes I, Pérez-Solis MA, Dias JA. Role of the intracellular domains of the human FSH receptor in G(alphaS) protein coupling and receptor expression. Mol Cell Endocrinol. 2007; 260-262:153-62.

19. Banerjee AA, Mahale SD. Role of the Extracellular and Intracellular Loops of Follicle-Stimulating Hormone Receptor in Its Function. Front Endocrinol. 2015;6:110.

20. Duvernay MT, Zhou F, Wu G. A conserved motif for the transport of G proteincoupled receptors from the endoplasmic reticulum to the cell surface. J Biol Chem. 2004;279:30741-50.

21. Zariñán T, Perez-Solís MA, Maya-Núñez G, Casas-González P, Conn PM, Dias $J A$, et al. Dominant negative effects of human follicle-stimulating hormone receptor expression-deficient mutants on wild-type receptor cell surface expression. Rescue of oligomerization-dependent defective receptor expression by using cognate decoys. Mol Cell Endocrinol. 2010;321:112-22.

22. Uchida S, Uchida H, Maruyama T, Kajitani T, Oda H, Miyazaki K, et al. Molecular analysis of a mutated FSH receptor detected in a patient with spontaneous ovarian hyperstimulation syndrome. PLoS One. 2013;8:e75478.

\section{Submit your next manuscript to BioMed Central and we will help you at every step:}

- We accept pre-submission inquiries

- Our selector tool helps you to find the most relevant journal

- We provide round the clock customer support

- Convenient online submission

- Thorough peer review

- Inclusion in PubMed and all major indexing services

- Maximum visibility for your research

Submit your manuscript at www.biomedcentral.com/submit

) Biomed Central 